\title{
How Well Does Body Mass Index (BMI) Predict Undiagnosed Hypertension and Diabetes in Indonesian Adults Community Population?
}

\author{
Rofingatul Mubasyiroh ${ }^{1}$, Nunik Kusumawardani ${ }^{1}$, Rika Rachmalina ${ }^{1}$, Prisca Petty Arfines ${ }^{1}$, \\ Tities Puspita ${ }^{1} \&$ Sudikno $^{1}$ \\ ${ }^{1}$ National Institute of Health Research and Development, Ministry of Health, Republic of Indonesia \\ Correspondence: Rofingatul Mubasyiroh, National Institute of Health Research and Development, Jl. Percetakan \\ Negara No.29, Central Jakarta, Jakarta, Indonesia. Tel: 62-21-4287-2393, Fax: 62-21-4287-2392. ORCID \\ numbers: 0000-0001-9989-8663.
}

Received: August 23, 2021 Accepted: September 17, 2021 Online Published: September 30, 2021

doi:10.5539/gjhs.v13n11p25

URL: https://doi.org/10.5539/gjhs.v13n11p25

\begin{abstract}
Background: Previous studies have reported that Body Mass Index (BMI) cut-off was related to non-communicable diseases. This study aimed to give the latest evidence related to the accuracy of BMI cut-off towards undiagnosed hypertension and diabetes in the Indonesian population.

Methods: This was A cross-sectional study that involved data of the 2018 national population-based health survey, with the samples were 15,516 male and female populations aged between 19 years old and above. This study only included those claimed to have never been diagnosed as suffering from diabetes and hypertension by health workers. Receiver operating characteristic (ROC) analysis was conducted to assess the optimal BMI cut-off. The logistic regression was performed to assess the association of BMI on undiagnosed hypertension and diabetes controlled by several variables.

Results: The average BMI sample was $24 \mathrm{~kg} / \mathrm{m}^{2}\left(\mathrm{SD}=4.6 \mathrm{~kg} / \mathrm{m}^{2}\right)$. The proportion of undiagnosed hypertension was $36.9 \%$, and $12.3 \%$ for the proportion of undiagnosed diabetes. According to the ROC, the result shows BMI was more sensitive to hypertension conditions compared to diabetes. BMI cut-off points at $23.9 \mathrm{~kg} / \mathrm{m}^{2}$ ( $\mathrm{AUC}=0.59 ; \mathrm{Se}=64.3 \% ; \mathrm{Sp}=53.4 \%$ ) was the optimum value to predict hypertension and $24.9 \mathrm{~kg} / \mathrm{m}^{2}$ (AUC $=0.55 ; \mathrm{Se}=53.1 \% ; \mathrm{Sp}=56.4 \%$ ) was the optimum for diabetes.

Conclusions: Based on the optimal AUC cut-off points for BMI which is around 0.5, BMI needs to be reconsidered as an anthropometric index in predicting undiagnosed hypertension and diabetes. And an assessment can be made using other anthropometric indices, such as waist circumference to predict undiagnosed hypertension and diabetes.
\end{abstract}

Keywords: BMI, cut-off points, undiagnosed hypertension, diabetes, prevention, Indonesia

\section{Introduction}

Non-communicable diseases (NCD) have been known as the ten highest cause of death in the world. It has caused around 41 million deaths worldwide, including about 15 million premature deaths at the age of 30-69 years (WHO, 2019). It also becomes the sixth-highest cause of years of life lost due to pain or disability. In general, NCD is the cause of most deaths and losses in Southeast Asia and Indonesia (Institute for Health Metrics and Evaluation, 2019).

National Indonesian Health Survey (RISKESDAS) showed the prevalence of diabetes mellitus (DM) at the age of 15 years and above based on the diabetes history was at $\%$ in 2018 which was higher than in 2013 (1.5\%). Based on the examination of blood glucose levels, the prevalence of DM also increased from 6.9\% (in 2013) to 8.5\% (in 2018). Meanwhile, the prevalence of hypertension history at the age of 18 years and above was at $9.5 \%$ (in 2013) to $8.4 \%$ (in 2018) and based on the measurement of blood pressure, was $25.8 \%$ (in 2013) to $34.1 \%$ (in 2018 ) (NIHRD-Indonesia MOH, 2013; NIHRD, 2018).

Several risk factors of the majority of NCDs included obesity, an unhealthy diet, and lack of physical activity. Many studies have shown the relationship between obesity, and the growth of non-communicable risk (Ndumele et 
al., 2016; Sunyer, 2010; Villareal, Apovian, Kushner, \& Klein, 2005; Ziraba, Fotso, \& Ochako, 2009). In Indonesia, the determination of BMI cut-off points is based on references by the WHO and some studies in Japan, Korea, India, and China (MOH Indonesia, 2003). Global standard by the WHO sets the normal safe cut-off for BMI as $24.9 \mathrm{~kg} / \mathrm{m}^{2}$ (WHO, 2004), and the BMI safe cut-off for Asians is $22.9 \mathrm{~kg} / \mathrm{m}^{2}$ (WHO, 2000). Several previous studies have analyzed and reported the BMI cut off with an increased risk of non-communicable diseases in the Indonesian population (Harahap, Widodo, \& Mulyati, 2005; Puspitasari, 2015; Triwinarto, Muljati, \& Jahari, 2012). Indonesian survey in 2004 with adult subjects ranging in age from 25-65 years has found that at a BMI value of $23 \mathrm{~kg} / \mathrm{m}^{2}$, the risk of degenerative disease associated with obesity was already detected. Triwinarto analyzed data from a national survey in 2007 , found a fairly good BMI cut-off point as an indicator of diabetes was $23 \mathrm{~kg} / \mathrm{m}^{2}$ in men and $24 \mathrm{~kg} / \mathrm{m}^{2}$ in women. The cut-off points of BMI which were quite good as an indicator of hypertension risk ranged from $22-23 \mathrm{~kg} / \mathrm{m}^{2}$ in men and $23-24 \mathrm{~kg} / \mathrm{m}^{2}$ in women.

However, from these studies, there are still no conclusive results that can be used as a reference with the results using the latest population data analysis. Therefore, this study aims to determine the accuracy of BMI cut-off points on the risk of undiagnosed hypertension and diabetes in the Indonesian population.

\section{Methods}

\subsection{Study Design}

This study analyzed data from the Indonesian national population-based health survey in 2018 (RISKESDAS). The sample size was the 300,000 households, randomly selected based on population sampling frame from the Indonesian Central Bureau of Statistics or Badan Pusat Statistik (BPS), which represents public health issues magnitude at the district or city level (515 districts within the 34 provinces). All household members who had lived for at least 6 months in the household and one food management in the selected household were interviewed face to face as a sample. Individual blood specimen was taken for laboratory test only in 25,000 households representing the national population. To explore public health answers and inspection procedures, structured interviews were carried out by enumerators who had been trained by the research team (Dany et al., 2020; NIHRD, 2018).

\subsection{Subject Criteria for Data Analysis}

Subjects for this study were adults aged 19 years and older. We analyzed cross-sectional data, so to strengthen the clarity of the relationship between BMI and NCD status, we only involved respondents who were not having a history or had ever been diagnosed with diabetes or hypertension, while those who were pregnant were excluded from the study. This study analyzed 15,516 individual data for the disease's history, behavior risk factors, social and economic indicators. Diabetes Mellitus was determined by a laboratory blood test, and hypertension was measured by digital blood pressure measurement.

\subsection{Ethical Considerations}

Ethical clearance of the national survey (RISKESDAS) had been approved by the Ethical Commission for Health Research, National Institute of Health Research and Development, Indonesian Ministry of Health in 2018 with No.: LB. 02.01/2/KE.267/2017.

\subsection{Measurement}

\subsubsection{Weight and Height}

The survey used two brands of digital scale bodyweight measurement, (AND and Family Dr), The AND scale had the capacity of 50-150 kg with 50-g accuracy; while the Family Dr scale ranged from 5-150 kg with 100-g accuracy. The scales were calibrated prior to data collection every day during the data collection.

Height was measured using a built-in device that follows the standardized height measurement and can be used flexibly in the respondent's home. Height measurement capacity was 2 meters with $0.1-\mathrm{cm}$ accuracy.

\subsubsection{Blood Pressure Measurement}

A digital blood pressure monitoring device (AND type UA-1020), was utilized to measure the blood pressure of the respondents twice with five minutes break. If there was a $10-\mathrm{mmHg}$ difference between the first and the second measurements, the third one was conducted after 10 minutes break.

\subsubsection{Blood Glucose Measurement}

Venous blood samples were collected for fasting or random plasma glucose testing. The measurement of fasting blood glucose required the respondents to have fasted for 10-14 hours before the test. Capillary blood samples were collected for an oral glucose tolerance test. This test was conducted two hours after the respondent received a glucose load of 75-gram anhydrous glucose powder for those who did not have diabetes history, and for those 
with a blood glucose of $\geq 126 \mathrm{mg} / \mathrm{dl}$ were given 72 gram of liquid food supplement containing 300 calories(NIHRD, 2018).

\subsection{Data Analysis}

\subsubsection{Definitions}

Hypertension case was determined as having a systolic blood pressure of $140 \mathrm{mmHg}$ and above or diastolic blood pressure of $90 \mathrm{mmHg}$ and above (according to JNC VIII) (Armstrong, 2013). This study also used the term undiagnosed hypertension in the analysis, as the respondent had never been diagnosed having hypertension before the survey.

Diabetes Mellitus case was determined by the following criteria: the blood glucose level should be $200 \mathrm{mg} / \mathrm{dl}$ and above with classic symptoms (polyuria, polydipsia, polyphagia, and weight loss); or the fasting blood sugar pressure should be $126 \mathrm{mg} / \mathrm{dl}$ and above; the blood sugar postprandial level was $200 \mathrm{mg} / \mathrm{dl}$ and above. This study used the term of undiagnosed DM in the analysis, as the respondent has not had any history of having DM prior to the survey. The independent variable of this study was BMI that obtained from the values of weight divided by the values of height squared.

This study used several social economy characteristics and behavior variables to perform the relationship analysis controls between BMI and NCDs. The variables included gender, age, level of education (which was marked by the last graduate certificate obtained), job status, marital status, gravida (for female), economic status (determined by BPS in which household assets as well an average income and expenditure were taken into account before categorizing wealth index

into 5 categories (lowest, lower-middle, middle, upper-middle and highest), types of residence, smoking habit in the last 1 month, alcohol consumption habit in the last 1 month, fruit and vegetable consumption (categorized as enough if at least 5 servings 7 days a week), risky food consumption (sweet food, sweetened drink, salty food, using a preservative, fatty, soft drink, and grilled), depression (categorized as having depression if at least 2 "yes" answers to questions 1-3 and a minimum of 2 "yes" answers to questions 4-10 according to The Mini-International Neuropsychiatric Interview (MINI) translated to Indonesian) and physical activity (physical activity is sufficient if vigorous physical activity is carried out for $>3$ days per week and MET minutes per week is $>1500$ or moderate physical activity is carried out for $>5$ days a week with an average duration of activity $>150$ minutes per week (or $>30$ minutes) per day).

\subsubsection{Statistical Analysis}

The analysis was performed using Stata version 15. Descriptive analysis was used to produce a description of the distribution of the sample according to the characteristics. The average value of several measurement and testing indicators is also obtained from the difference in the average test results (t-test). Receiver operating character (ROC) was performed to measure the optimal BMI cut-off by calculating the Youden index (Sensitivity plus Specificity-1) (Chua, Zalilah, Haemamalar, Norhasmah, \& Geeta, 2017; Gharipour et al., 2014).

In determining the optimal decision by considering the point on the ROC curve where the sensitivity (Se) and specificity $(\mathrm{Sp})$ are equal; the point on the curve with the minimum distance from the upper-left corner of the unit square; and the point where the index is maximum.

In addition, the Area Under Curve (AUC) is used to measure having a BMI cut-off. The ROC curve provides a graphical illustration of the trade-off mentioned above between the Se and Sp tests and illustrates the TP (Se) level against the FP (1 - Sp) level for every cut-off being tested. Each point on the ROC curve corresponds to a certain cut-off and its Se and Sp. Determining the cut-off requires consideration between Se and Sp. In certain cases, especially in infectious diseases, Se will take precedence over Sp. Under certain circumstances, however, Sp may be of greater concern than $\mathrm{Se}$, when further testing is not feasible. If there is no preference between $\mathrm{Se}$ and $\mathrm{Sp}$, a reasonable approach is to maximize both indices(Altman \& Bland, 1994).

Finally, logistic regression was performed to assess the association of BMI with undiagnosed diabetes and hypertension controlled by the social economy and behavior variables. The odds ratio is calculated as the ratio for having undiagnosed hypertension and diabetes at the optimal BMI cut-off value compared to individuals with a low BMI $\left(<18.5 \mathrm{~kg} / \mathrm{m}^{2}\right)$.

\section{Results}

Descriptive analysis has shown a fair distribution of male and female groups and higher populations on productive age. Nearly three-quarters of the samples had educational levels ranging from no education to junior high graduates. More than half of the sample population was economically productive or has a job. 
Tabel 1. Social economy and behavior characteristics distribution

\begin{tabular}{|c|c|c|c|}
\hline & Male $(N=7682)$ & Female $(\mathrm{N}=7834)$ & Overall $(\mathrm{N}=15516)$ \\
\hline \multicolumn{4}{|c|}{ Age groups (yrs) } \\
\hline $19-24$ & 6.5 & 8.5 & 7.5 \\
\hline $25-34$ & 14.8 & 19.2 & 17.0 \\
\hline $35-44$ & 22.5 & 26.6 & 24.6 \\
\hline $45-54$ & 25.3 & 24.1 & 24.7 \\
\hline $55-64$ & 19.4 & 14.5 & 16.9 \\
\hline $65-74$ & 8.6 & 5.5 & 7.0 \\
\hline $75+$ & 2.9 & 1.7 & 2.3 \\
\hline \multicolumn{4}{|c|}{ Education level } \\
\hline Low & 70.5 & 75.3 & 72.9 \\
\hline High & 29.5 & 24.7 & 27.1 \\
\hline \multicolumn{4}{|c|}{ Marital status } \\
\hline Single & 15.3 & 20.1 & 17.7 \\
\hline Married & 84.7 & 79.9 & 82.3 \\
\hline \multicolumn{4}{|l|}{ Occupation } \\
\hline No & 10.1 & 51.4 & 30.9 \\
\hline Has a job & 89.9 & 48.6 & 69.1 \\
\hline \multicolumn{4}{|c|}{ Economic status } \\
\hline Quintile 1st & 26.0 & 26.9 & 26.4 \\
\hline Quintile 2nd & 20.6 & 21.0 & 20.8 \\
\hline Quintile 3rd & 18.6 & 18.7 & 18.7 \\
\hline Quintile 4th & 17.6 & 17.6 & 17.6 \\
\hline Quintile 5th & 17.2 & 15.9 & 16.6 \\
\hline \multicolumn{4}{|c|}{ Type of residence } \\
\hline Rural & 52.1 & 50.8 & 51.5 \\
\hline Urban & 47.9 & 49.2 & 48.6 \\
\hline \multicolumn{4}{|c|}{ Smoking status } \\
\hline Never & 23.0 & 95.2 & 59.5 \\
\hline Former & 11.2 & 1.8 & 6.4 \\
\hline Current & 65.8 & 3.0 & 34.1 \\
\hline \multicolumn{4}{|c|}{ Alcohol consumption } \\
\hline No & 97.1 & 99.9 & 98.5 \\
\hline Yes & 2.9 & 0.1 & 1.5 \\
\hline \multicolumn{4}{|c|}{ Physical activity } \\
\hline Active & 73.9 & 79.9 & 76.9 \\
\hline Inactive & 26.2 & 20.2 & 23.1 \\
\hline \multicolumn{4}{|c|}{ Fruits/Vegetables consumption } \\
\hline Enough & 4.8 & 4.6 & 4.7 \\
\hline Not enough & 95.3 & 95.4 & 95.3 \\
\hline \multicolumn{4}{|l|}{ Depression } \\
\hline No & 94.0 & 92.5 & 93.2 \\
\hline Yes & 6.0 & 7.5 & 6.8 \\
\hline Total & 49.51 & 50.49 & 100.0 \\
\hline
\end{tabular}


As described in Table 2. The mean value of body weight, height, and systole blood pressure, was higher in males than females. Meanwhile, diastolic blood pressure, fasting blood glucose, and post-prandial blood glucose were significantly higher in females than males.

As described in Table 3. the statistical analysis of the t-test found that both males and females with hypertension significantly had higher BMI $\left(25.2 \mathrm{~kg} / \mathrm{m}^{2}\right)$ compared to those without hypertension $\left(23.2 \mathrm{~kg} / \mathrm{m}^{2}\right)$. Similarly, those with diabetes mellitus had a higher BMI $\left(24.8 \mathrm{~kg} / \mathrm{m}^{2}\right)$ compare to those non-DM population $\left(23.8 \mathrm{~kg} / \mathrm{m}^{2}\right)$.

Table 2. Mean value of biological and biochemical risk factors for major NCDs

\begin{tabular}{lllll}
\hline & \multicolumn{3}{c}{ Mean+SD } & p-value \\
\cline { 2 - 4 } & Overall & Male & Female & $<0.001$ \\
\hline Weight $(\mathrm{kg})$ & $57.5 \pm 11.8$ & $59.1 \pm 11.6$ & $56.4 \pm 11.7$ & $<0.001$ \\
Height $(\mathrm{m})$ & $155 \pm 8.3$ & $161.5 \pm 6.7$ & $150.4 \pm 5.9$ & $<0.001$ \\
IMT $\left(\mathrm{kg} / \mathrm{m}^{2}\right)$ & $24 \pm 4.6$ & $22.6 \pm 3.9$ & $24.9 \pm 4.8$ & 0.016 \\
Systole Blood Pressure Average $(\mathrm{mmHg})$ & $130.2 \pm 21.8$ & $130.7 \pm 20.1$ & $129.8 \pm 22.8$ & $<0.001$ \\
Diastolic Blood Pressure Average $(\mathrm{mmHg})$ & $83.4 \pm 12.0$ & $82.4 \pm 11.7$ & $84.1 \pm 12.1$ & 0.110 \\
Current Blood sugar $(\mathrm{mg} / \mathrm{dl})$ & $140.1 \pm 65.5$ & $151.8 \pm 72.8$ & $129.4 \pm 56.8$ & 0.001 \\
Fasting blood sugar $(\mathrm{mg} / \mathrm{dl})$ & $100 \pm 25.7$ & $99.1 \pm 20.1$ & $100.6 \pm 29.0$ & $<0.001$ \\
Post prandial blood sugar $(\mathrm{mg} / \mathrm{dl})$ & $142.7 \pm 48.4$ & $136.3 \pm 44.1$ & $147.1 \pm 50.7$ & \\
\hline
\end{tabular}

Table 3. BMI values according to the different metabolic risk factors in male and female subjects

\begin{tabular}{|c|c|c|c|c|c|c|c|}
\hline & & Overall & & Male & & Female & \\
\hline & & $\mathrm{BMI}+\mathrm{SD}\left(\mathrm{kg} / \mathrm{m}^{2}\right)$ & $p$-value & $\mathrm{BMI}+\mathrm{SD}\left(\mathrm{kg} / \mathrm{m}^{2}\right)$ & $p$-value & $\mathrm{BMI}+\mathrm{SD}\left(\mathrm{kg} / \mathrm{m}^{2}\right)$ & $p$-value \\
\hline \multirow{2}{*}{ Hypertension } & No & $23.2+4.3$ & \multirow{2}{*}{$<0.001$} & $22.0 \pm 3.6$ & \multirow{2}{*}{$<0.001$} & $22.5 \pm 3.8$ & \multirow{2}{*}{$<0.001$} \\
\hline & Yes & $25.2 \pm 4.9$ & & $23.7 \pm 4.3$ & & $23.2 \pm 4.5$ & \\
\hline \multirow{2}{*}{ Diabetes } & No & $23.8 \pm 4.5$ & \multirow{2}{*}{$<0.001$} & $24.2 \pm 4.5$ & \multirow{2}{*}{$<0.001$} & $24.8 \pm 4.7$ & \multirow{2}{*}{$<0.001$} \\
\hline & Yes & $24.8 \pm 5.0$ & & $26.1 \pm 5.0$ & & $25.8 \pm 5.1$ & \\
\hline
\end{tabular}

This study showed several models of BMI cut-off that has strongly related to diabetes and hypertension. Table 4 described the area under the curve, sensitivity, and specificity values, as well as from the optimal BMI cut-off points. It can be seen from the BMI cut-off at $24.9 \mathrm{~kg} / \mathrm{m}^{2}(\mathrm{AUC}=0.55 ; \mathrm{Se}=53.1 \% ; \mathrm{Sp}=56.4 \%)$ as the optimum values to predict diabetes in the overall samples. In contrast, seen by gender, these values had a different pattern, the optimum BMI cut-off point in males was at $23.9 \mathrm{~kg} / \mathrm{m}^{2}(\mathrm{AUC}=0.54 ; \mathrm{Se}=47.1 \%$; $\mathrm{Sp}=61.6 \%)$. In females, the cut-off value was at $24.9 \mathrm{~kg} / \mathrm{m}^{2}$ ( $\left.\mathrm{AUC}=0.54 ; \mathrm{Se}=61.5 \% ; \mathrm{Sp}=46.8 \%\right)$ to predict the occurrence of diabetes. To predict the occurrence of hypertension, the optimum BMI cut-off point was at $23.9 \mathrm{~kg} / \mathrm{m}^{2}$ in both sexes (AUC $=0.59 ; \mathrm{Se}=64.3 \% ; \mathrm{Sp}=53.4 \%$ ). The optimum cut-off for BMI to predict hypertension was at $23.9 \mathrm{~kg} / \mathrm{m}^{2}$ in males $(\mathrm{AUC}=0.59 ; \mathrm{Se}=51.6 \% ; \mathrm{Sp}=66.8,0 \%)$, while in female it was at $24.9 \mathrm{~kg} / \mathrm{m}^{2} \quad(\mathrm{AUC}=0.58 ; \mathrm{Se}=64.1 \%$; $\mathrm{Sp}=51.7 \%)$. 
Table 4. The AUC, optimal BMI cut-off values, sensitivities, and specificities stratified by sex for the prediction of undiagnosed diabetes and hypertension

\begin{tabular}{lllccc}
\hline \multirow{2}{*}{ Both sexes } & AUC & Cut-off $\left(\mathrm{kg} / \mathrm{m}^{2}\right)$ & Sensitivity (\%) & Specificity (\%) \\
& Diabetes & 0.55 & 24.9 & 53.1 & 56.4 \\
\multirow{2}{*}{ Male } & Hypertension & 0.59 & 23.9 & 64.3 & 53.4 \\
& Diabetes & 0.54 & 23.9 & 47.1 & 61.6 \\
\multirow{2}{*}{ Female } & Hypertension & 0.59 & 23.9 & 51.6 & 66.8 \\
& Diabetes & 0.54 & 24.9 & 61.5 & 46.8 \\
& Hypertension & 0.58 & 24.9 & 64.1 & 51.7 \\
\hline
\end{tabular}

The substantial risks of diabetes and hypertension by the distribution of BMI are shown in Table 5. The optimum cut-off for diabetes risk $\left(24.9 \mathrm{~kg} / \mathrm{m}^{2}\right)$ had an OR-value of 1.4. Meanwhile, the optimum point for hypertension risk $\left(23.9 \mathrm{~kg} / \mathrm{m}^{2}\right)$ had an OR-value of OR=2.8. In general, at the same BMI value, the substantial risk of hypertension was higher than that of diabetes.

Table 5. Adjusted BMI Odds Ratio towards undiagnosed diabetes and hypertension

\begin{tabular}{llcc}
\hline & & BMI $\left(\mathrm{kg} / \mathrm{m}^{2}\right)$ & OR adjusted \\
\hline \multirow{2}{*}{ Both sexes } & Diabetes & 24.9 & 1.4 \\
& Hypertension & 23.9 & 2.8 \\
\hline \multirow{2}{*}{ Male } & Diabetes & 23.9 & 1.6 \\
& Hypertension & 23.9 & 2.9 \\
\hline \multirow{2}{*}{ Female } & Diabetes & 24.9 & 1.3 \\
& Hypertension & 24.9 & 3.2 \\
\hline
\end{tabular}

Note. OR-adjusted for age, education level, marital status, occupation, economic status, type of residence, smoking, alcohol consumption, physical activity, fruits/vegetables consumption, depression.

\section{Discussion}

The main finding of this study described that BMI cut-off for NCDs risk can be specifically formulated based on the relationship between BMI and NCDs outcome (undiagnosed diabetes or hypertension) for the Indonesian population. The BMI cut-off values to predict undiagnosed hypertension $23.9 \mathrm{~kg} / \mathrm{m}^{2}$ (AUC=0.59; $\mathrm{Se}=64.3 \%$; $\mathrm{Sp}=53.4 \%$ ) and for undiagnosed diabetes $24.9 \mathrm{~kg} / \mathrm{m}^{2}$ ( $\left.\mathrm{AUC}=0.55 ; \mathrm{Se}=53.1 \% ; \mathrm{Sp}=56.4 \%\right)$. This present study also discovers that the male group has the same BMI cut-off points for diabetes and hypertension $\left(23.9 \mathrm{~kg} / \mathrm{m}^{2}\right)$. Similarly, females had the same cut-off points for diabetes and hypertension at $24.9 \mathrm{~kg} / \mathrm{m}^{2}$. These results are almost the same as those of two studies in China (a cohort study and cross-sectional study) which find the BMI cut-off points for hypertension and diabetes were at $23 \mathrm{~kg} / \mathrm{m}^{2}(\mathrm{Se}=66.3 \%, \mathrm{Sp}=55.5 \%, \mathrm{AUC}=0.558)$ and $24 \mathrm{~kg} / \mathrm{m}^{2}$, respectively ( $\mathrm{Se}=60.6 \%, \mathrm{Sp}=61.4 \%, \mathrm{AUC}=0.55)$ (He et al., 2015; Wildman, Gu, Reynold, Duan, \& He, 2004). Other cross-sectional study in China found the age group of 20-74 years showed the BMI cut-off points for hypertension in males were at $24 \mathrm{~kg} / \mathrm{m}^{2}(\mathrm{Se}=74.68 \%, \mathrm{Sp}=58.82 \%, \mathrm{AUC}=0.58)$ and in females $(\mathrm{Se}=71.49 \%$, $\mathrm{Sp}=63.32 \%, \mathrm{AUC}=0.66)$ (Feng et al., 2012).

The WHO recommends a normal BMI cut-off at a point of $25 \mathrm{~kg} / \mathrm{m}^{2}$ taking into account the general population, risk of death, except ethnic varieties (Hsu, Araneta, Kanaya, \& Chiang, 2015). A study compared body fat percentage and BMI of the Indonesian population living in Sumatra compared to the Caucasians living in Wageningen, the Netherlands. The results showed that Indonesians who have the same body fat percentage, age, and sex generally have a BMI of $2.9 \mathrm{~kg} / \mathrm{m}^{2}$ lower than the Dutch. This study concludes that the cut-off points for obesity in Indonesia should be lower than the WHO recommended cut-off $\left(27 \mathrm{~kg} / \mathrm{m}^{2}\right.$ instead of $\left.30 \mathrm{~kg} / \mathrm{m}^{2}\right)($ Gurrici, Hartriyanti, Hautvast, \& Deurenberg, 1998).

This present study further shows that these values were lower than those found in the Caucasian population. Related to the current study findings, it may be that Asians incline to have a higher body fat mass (Deurenberg, 
Deurenberg, \& Guricci, 2002; Wang et al., 1994). The correlation between BMI and body was assumed to be influenced by age, gender, and ethnicity (Carpenter et al., 2013). Indonesia as well as Taiwan populations have higher body fat mass but lower BMI in comparison with Caucasians (Chang et al., 2003; Gurrici et al., 1998). Cultural and eating habits, physical activity, and lifestyle differences may explain these differences (Merlo, Asplund, Lynch, Råstam, \& Dobson, 2004)

Furthermore, our study reinforces high BMI is one of the common risk factors for major NCDs, such as diabetes and hypertension. In short, the substantial BMI risk for hypertension is generally higher than diabetes. Research in China also shows similar results that the BMI limit for the risk of hypertension was higher than diabetes (Feng et al., 2012), but other studies reported opposite results in Japan population with Brazilian ancestry (Simony, Roberta, \& Ferreira, 2007). A previous study in Indonesia shows the $23 \mathrm{~kg} / \mathrm{m}^{2}$ BMI had an OR-value of 2.1 for the risk of hypertension (Harahap et al., 2005). However, our study, at this point, indicates an OR-value of 2.8. Even it finds $22 \mathrm{~kg} / \mathrm{m}^{2}$ BMI showed an OR-value of 2.2 for the risk of hypertension. A previous study in Indonesia showed that $23 \mathrm{~kg} / \mathrm{m} 2 \mathrm{BMI}$ indicated an OR-value of 1.3 for the risk of diabetes (Harahap et al., 2005).

Even though BMI was positively related to the increased risk of diabetes and hypertension, the prediction of those results was moderate ( $\mathrm{AUC}=0.6-0.8$ ) for the Asian population (Lin et al., 2002; $\mathrm{R}$ et al., 2008; Weng et al., 2006). The moderate AUC value indicated that other factors might also contribute to the risk of diabetes and hypertension. Therefore, the BMI cut-off based on sensitivity-specificity value is considered as a more useful threshold to determine weight gain, recommendation, and clinical proceeding for public health, except to screen or early detection of diabetes and hypertension risk (Tuan, Adair, He, \& Popkin, 2008)

Based on the results of the area under curve produced in this study, it did not reach a value of 0.6 , which means that BMI is less significant for diagnosing the incidence (Swets, 1988) of undiagnosed diabetes and hypertension for Indonesian adults. BMI is indeed a simple anthropometric index that is often used to determine disease risk, but BMI has several weaknesses. Among them, lean mass and fat mass could not be differentiated for a particular BMI based on age, gender, and race. Second, the fat distribution could not be distinguished by BMI, whilst it has been generally accepted that visceral adiposity plays more an important role in developing insulin resistance and diabetes rather than overall adiposity (Haghighatdoost, Amini, Feizi, \& Iraj, 2017).

BMI does not distinguish between fat and lean body mass, so people who are short or muscular may be misidentified (Millar, Perry, \& Phillips, 2015). BMI sensitivity is low in differentiating people with hypertension. Perhaps because BMI cannot measure the fat distribution and differentiate between adipose tissue and muscle mass. The associations were weak between BMI and body fat percentage in Asians compared to other ethnic groups, and the large proportion of people with high body fat remained undetected based on their BMI. Screening using BMI alone will underestimate hypertension (Tee, Gan, \& Lim, 2020). BMI cannot distinguish body parts or proportions because BMI is related to general fat concentration. Cross-sectional studies in Turkey, Malaysia, and Brazil, as well as a prospective cohort in Iran, showed abdominal obesity as represented by the Waist: height ratio (WHtR) index was the best predictor of hypertension, diabetes, outperforming BMI (Caminha et al., 2017; Chan \& Woo, 2010; Chua et al., 2017; Hadaegh, Shafiee, \& Azizi, 2009). In China, the cross-sectional study also showed abdominal circumference in addition to the Waist: height ratio (WHtR) both predicting hypertension and diabetes (Zeng et al., 2014). The results of 35 cross-sectional studies with subjects aged 18-74 years published from 19752009 show that most of these cross-sectional studies revealed that the AUC was slightly higher for WC or WHR than for BMI (Qiao \& Nyamdorj, 2010).

The limitations of this study include the study design which cannot be used to determine causal inference. Nonetheless, this study had already tried to address this issue by selecting the data based on those who were not having a history or have ever been diagnosed with diabetes or hypertension as inclusion criteria mentioned in the method sections. A strong point of this study is the use of national data that covers the whole population aged 19 years and above, which enables these findings to represent the Indonesian adult population.

\section{Conclusion}

The finding shows the BMI cut off as having obesity, a risk factor of major NCDs, was lower than determined by the WHO $\left(30 \mathrm{~kg} / \mathrm{m}^{2}\right)$ and the Indonesian government $\left(27 \mathrm{~kg} / \mathrm{m}^{2}\right)$. The optimum BMI cut-off for the risk of hypertension was at $23.9 \mathrm{~kg} / \mathrm{m}^{2}$ and $24.9 \mathrm{~kg} / \mathrm{m}^{2}$ for diabetes. On the same BMI point, the risk of hypertension was higher compared with diabetes. Notably, it suggests that BMI was more strongly associated with hypertension. However, based on the optimal AUC cut-off points for BMI which is around 0.5, it is recommended to combine other anthropometric indices to predict the risk of people experiencing hypertension and diabetes. 


\section{Acknowledgments}

The authors would like to express gratitude to the Head of the National Institute of Health Research and Development, the Indonesian Ministry of Health, which allowed us to do the research.

\section{Authors' Contributions}

RM and NK: Main contributor responsible for conceptualizing the study design and framework, proposal writing, data management and analysis, discussion, and editing of the final draft for publication. RR, PA, TP, and SD: background, methods, data analysis, preparing the first draft of publication, dummy tables, and figures, discussion, editing of the final draft for publication. All authors listed in this manuscript have carefully read, checked the validity and legitimacy of the data, and given their approval before its submission and publication.

\section{Funding}

No funding was received.

\section{Competing Interests Statement}

The authors declare that they have no competing interests.

\section{References}

Altman, D. G., \& Bland, J. M. (1994). Statistics Notes: Diagnostic tests 2: Predictive values. BMJ, 309(6947), 102. https://doi.org/https://doi.org/10.1136/bmj.309.6947.102

Armstrong, C. (2013). JNC 8 Guidelines for The Management of Hypertension in Adult. American Family Physician, 90(7), 503-504. https://doi.org/10.1038/sj.ejen.1600637

Caminha, T. C. S., Ferreira, H. S., Costa, N. S., Nakano, R. P., Carvalho, R. E. S., Xavier, A. F. S., \& Assunção, M. L. (2017). Waist-to-height ratio is the best anthropometric predictor of hypertension: A population-based study with women from a state of northeast of Brazil. Medicine (United States), 96(2). https://doi.org/https://doi.org/10.1097/MD.0000000000005874

Carpenter, C. L., Yan, E., Chen, S., Hong, K., Arechiga, A., Kim, W. S., ... Heber, D. (2013). Body Fat and Body-Mass Index among a Multiethnic Sample of College-Age Men and Women. Journal of Obesity, 2013(8), 19-21. https://doi.org/https://doi.org/10.1155/2013/790654

Chan, R. S. M., \& Woo, J. (2010). Prevention of Overweight and Obesity : How Effective is the Current Public Health Approach. International Journal of Environmental Research and Public Health, 7, 765-783. https://doi.org/https://doi.org/10.3390/ijerph7030765

Chang, C., Wu, C., Chang, C., Yao, W., Yang, Y., Wu, J., \& Lu, F. (2003). Low body mass index but high percent body fat in Taiwanese subjects : implications of obesity cutt-offs. International Journal of Obesity, 27, 253-259. https://doi.org/: https://doi.org/10.1038/sj.ijo.802197

Chua, E. Y., Zalilah, M. S., Haemamalar, K., Norhasmah, S., \& Geeta, A. (2017). Obesity indices predict hypertension among indigenous adults in Krau Wildlife Reserve, Peninsular Malaysia. Journal of Health, Population, and Nutrition, 36(1), 24. https://doi.org/https://doi.org/10.1186/s41043-017-0102-4

Dany, F., Dewi, R. M., Tjandrarini, D. H., Pradono, J., Delima, D., Sariadji, K., ... Kusumawardani, N. (2020). Urban-rural distinction of potential determinants for prediabetes in Indonesian population aged $\geq 15$ years: A cross-sectional analysis of Indonesian Basic Health Research 2018 among normoglycemic and prediabetic individuals. BMC Public Health, 20(1), 1-9. https://doi.org/https://doi.org/10.1186/s12889-020-09592-7

Deurenberg, P., Deurenberg, M., \& Guricci, S. (2002). Asians are different from Caucasians and from each other in their body mass index/body fat per cent relationship. Obesity Review, 3(3). https://doi.org/https://doi.org/10.1046/j.1467-789X.2002.00065.x

Feng, R., Zhao, C., Wang, C., Niu, Y., Li, K., Guo, F., ... Li, Y. (2012). BMI is Strongly Associated With Hypertension, and Waist Circumference is Strongly Associated With Type 2 Diabetes and Dyslipidemia , in $\begin{array}{lllll}\text { Northern Chinese Adults. Journal Epidemiology, 22(4), 317-323. } & \end{array}$ https://doi.org/https://doi.org/10.2188/jea.JE20110120

Gharipour, M., Sadeghi, M., Dianatkhah, M., Bidmeshgi, S., Ahmadi, A., Tahri, M., \& Sarrafzadegan, N. (2014). The cut-off values of anthropometric indices for identifying subjects at risk for metabolic syndrome in iranian elderly men. Journal of Obesity, 2014. https://doi.org/: https://doi.org/10.1155/2014/907149

Gurrici, S., Hartriyanti, Y., Hautvast, J., \& Deurenberg, P. (1998). Relationship between body fat and body mass 
index : differences between Indonesians and Dutch Caucasians. European Journal of Clinical Nutrition, 52(11), 779-783. https://doi.org/https://doi.org/10.1038/sj.ejcn.1600637

Hadaegh, F., Shafiee, G., \& Azizi, F. (2009). Anthropometric predictors of incident type 2 diabetes mellitus in Iranian women. Ann Saudi Med, 29(3), 194-200. https://doi.org/https://doi.org/10.5144/0256-4947.51788

Haghighatdoost, F., Amini, M., Feizi, A., \& Iraj, B. (2017). Are body mass index and waist circumference significant predictors of diabetes and prediabetes risk: Results from a population based cohort study. World Journal of Diabetes, 8(7), 365. https://doi.org/https://doi.org/10.4239/wjd.v8.i7.365

Harahap, H., Widodo, Y., \& Mulyati, S. (2005). Determining Cut-Off Points Of Body Mass Index For Obesity Associated With Degenerative Diseases In Indonesia. Gizi Indonesia, 31.

He, W., Li, Q., Yang, M., Jiao, J., Ma, X., Zhou, Y., ... Heymsfield, S. B. (2015). Lower BMI Cutt-offs to Define Overweight and Obesity in China. Obesity, 23(3), 684-691. https://doi.org/https://doi.org/10.1002/oby.20995

Hsu, W. C., Araneta, M. R. G., Kanaya, A. M., \& Chiang, J. L. (2015). BMI Cut Points to Identify At-Risk Asian Americans for Type 2 Diabetes Screening. 150 Diabetes Care, 38(January), 150-158. https://doi.org/https://doi.org/10.2337/dc14-2391

Institute for Health Metrics and Evaluation. (2019). GBD compare. Retrieved from https://vizhub.healthdata.org/gbd-compare/

Lin, W. Y., Lee, L. T., Chen, C. Y., Lo, H., Hsia, H. H., Liu, I. L., ... Huang, K. C. (2002). Optimal cut-off values for obesity: Using simple anthropometric indices to predict cardiovascular risk factors in Taiwan. International Journal of Obesity, 26(9), 1232-1238. https://doi.org/https://doi.org/10.1038/sj.ijo.0802040

Merlo, J., Asplund, K., Lynch, J., Råstam, L., \& Dobson, A. (2004). Population Effects on Individual Systolic Blood Pressure: A Multilevel Analysis of the World Health Organization MONICA Project. American Journal of Epidemiology, 159(12), 1168-1179. https://doi.org/https://doi.org/10.1093/aje/kwh160

Millar, S. R., Perry, I. J., \& Phillips, C. M. (2015). Assessing cardiometabolic risk in middle-aged adults using body mass index and waist-height ratio: Are two indices better than one? A cross-sectional study. Diabetology and Metabolic Syndrome, 7(1), 1-11. https://doi.org/https://doi.org/10.1186/s13098-015-0069-5

MOH Indonesia. (2003). Pedoman praktis terapi gizi medis. Jakarta.

Ndumele, C. E., Matsushita, K., Lazo, M., Belio, N., Blumenthal, R., Gerstenblith, G., ... Coresh, J. (2016). Obesity and Subtypes of Incident Cardiovascular Disease. Journal of the American Heart Association, 1-10. https://doi.org/https://doi.org/10.1161/JAHA.116.003921

NIHRD-Indonesia MOH. (2013). Riset Kesehatan Dasar (RISKESDAS) 2013. Jakarta: NIHRD-MOH. https://doi.org/1 Desember 2013

NIHRD, I. M. (2018). Laporan Nasional Riset Kesehatan Dasar 2018. Jakarta: Lembaga Penerbit Badan Litbangkes.

Puspitasari, D. R. (2015). Nilai Titik Potong/ Cut-Off Point Lingkar Pinggang Dan Indeks Masa Tubuh Orang Indonesia Untuk Memprediksi Diabetes Mellitus Dengan Rasio Kemungkinan Positif Terbaik.

Qiao, Q., \& Nyamdorj, R. (2010). Is the association of type II diabetes with waist circumference or waist-to-hip ratio stronger than that with body mass index. European Journal of Clinical Nutrition, 64(1), 30-34. https://doi.org/https://doi.org/10.1038/ejen.2009.93

R, H., James, W. P. T., Barzi, F., Patel, J. ., Lear, S. A., Suriyawongpaisal, P., ... Woodward, M. (2008). Ethnic comparisons of the cross-sectional relationships between measures of body size with diabetes and $\begin{array}{llll}\text { hypertension. } & \text { Obesity } & \text { Reviews, } & \text { 53-61. }\end{array}$ https://doi.org/https://doi.org/10.1111/j.1467-789X.2007.00439.x

Simony, R. F., Roberta, S., \& Ferreira, G. (2007). Which body mass index is best associated with risk of diabetes mellitus and hypertension in a Japanese-Brazilian population? Que valor de índice de massa corporal melhor se associa a risco de diabetes mellitus e hipertensão em nipo-brasileiros? ARTIGO, 23(2), 297-304. https://doi.org/10.1590/S0102-311X2007000200005

Sunyer, X. P. (2010). The Medical Risks of Obesity. Postgrad Med, 121(6), 21-33. https://doi.org/https://doi.org/10.3810/pgm.2009.11.2074.The

Swets, J. A. (1988). Measuring the Accuracy of Diagnostic Systems. Science, 240(4857), 1285-1293. https://doi.org/10.1126/science.3287615 
Tee, J. Y. H., Gan, W. Y., \& Lim, P. Y. (2020). Comparisons of body mass index, waist circumference, waist-to-height ratio and a body shape index (ABSI) in predicting high blood pressure among Malaysian $\begin{array}{llllll}\text { adolescents: } & \text { A cross-sectional study. }\end{array}$ https://doi.org/https://doi.org/10.1136/bmjopen-2019-032874

Triwinarto, A., Muljati, S., \& Jahari, A. B. (2012). Cut-Off Point Body Mass Index (Bmi) And Abdominal Circumference As Indicators Of Diabetes And Hypertension Risks Among The Indonesian Adults. Penelitian Gizi Makanan, 35(2), 119-135.

Tuan, N. T., Adair, L. S., He, K., \& Popkin, B. M. (2008). Optimal Cutt-off Values for Overweight: Using Body Mass Index to Predict Incidence of Hypertension in 18-to 65-Year-Old Chinese Adults 1,2. The Journal of Nutrition Nutritional Epidemiology J. Nutr (Vol. 138). https://doi.org/10.1093/jn/138.7.1377

Villareal, D. T., Apovian, C. M., Kushner, R. F., \& Klein, S. (2005). Obesity in older adults : technical review and position statement of the American Society for Nutrition and NAASO, The Obesity. American Journal Clinical Nutrition, (April). https://doi.org/10.1093/ajen/82.5.923

Wang, J., Thornton, J. C., Russell, M., Burastero, S., Heymsfield, S., \& Pierson, R. N. (1994). Asians have lower body mass index ( BMI ) but higher percent body fat than do whites: Comparisons of anthropometric measurements Asians have lower body mass index ( BMI ) but higher percent body fat than do whites : comparisons of anthropometric. American Journal Clinical Nutrition, (August), 23-28. https://doi.org/10.1093/ajcn/60.1.23

Weng, X., Liu, Y., Ma, J., Wang, W., Yang, G., \& Caballero, B. (2006). Use of body mass index to identify obesity-related metabolic disorders in the Chinese population. European Journal of Clinical Nutrition, 60(8), 931-937. https://doi.org/https://doi.org/10.1038/sj.ejcn.1602396

WHO. (2000). Redifining obesity and its treatment .pdf.

WHO. (2004). Appropriate body-mass index for Asian populations and its implications for policy and intervention strategies. The Lancet, 363, 157-163. https://doi.org/10.1016/S0140-6736(03)15268-3

WHO. (2019). Ten threats to global health in 2019. Retrieved from https://www.who.int/emergencies/ten-threats-to-global-health-in-2019

Wildman, R. P., Gu, D., Reynold, K., Duan, X., \& He, J. (2004). Appropriate body mass index and waist circumference cutt-offs for categorization of overweight and central adiposity among Chinese. American Journal Clinical Nutrition, 1129-1135. https://doi.org/10.1093/ajcn/80.5.1129

Zeng, Q., He, Y., Dong, S., Zhao, X., Chen, Z., Song, Z., ... Wang, Y. (2014). Optimal cut-off values of BMI, waist circumference and waist:height ratio for defining obesity in Chinese adults. British Journal of Nutrition, $112(10), 1735-1744$. https://doi.org/10.1017/S0007114514002657

Ziraba, A. K., Fotso, J. C., \& Ochako, R. (2009). Overweight and obesity in urban Africa : A problem of the rich or the poor? BMC Public Health, 9(465), 1-9. https://doi.org/https://doi.org/10.1186/1471-2458-9-465

\section{Copyrights}

Copyright for this article is retained by the author(s), with first publication rights granted to the journal.

This is an open-access article distributed under the terms and conditions of the Creative Commons Attribution license (http://creativecommons.org/licenses/by/4.0/). 